\title{
MESTKEVERS VAN HET GESLACHT APHODIUS ILL. ALS VIJANDEN VAN DE CHAMPIGNON-KULTUUR.
}

In de eerste dagen van September 1916 bracht mij de Heer IDE alhier een aantal kevertjes, waarvan sommige geheel zwart, de meesten echter zwart met roode dekschilden, welke hij had meegebracht van de champigonkweekerij "Aurora" van den Heer Polvliet te Ugchelen bij Apeldoorn.

Volgens dezen Heer werden deze kevertjes voor zijne champignonkultuur vrij schadelijk, zoowel door het omwoelen van den paardemest, die voor de kultuur der champignons dient, als door het opeten van het daarin aanwezige zwamdradennet of mycelium, waaruit de vruchtlichamen of paddestoelen opgroeien, die onder den naam van "champignons" worden gegeten.

De kevertjes werden door mij dadelijk herkend als behoorende tot de zoogenaamde "mestkevers" van het geslacht A phodius IIl.

De mestkevers worden gerekend tot de familie der Plaatsprietigen of Lamellicornia, waartoe o. a. de Meikever behoort. Hunnen naam ontleenen de mestkevers aan het feit, dat de vrouwelijke kevers hare eieren leggen in mest, waarin de engerling-achtige larven leven en waarmee deze zich voeden, evenals de volwassen kevers zelven. Schadelijk aan planten worden de mestkevers gewoonlijk niet.

Het geslacht Aphodius omvat in 't algemeen kleinere mestkeversoorten. De kevertjes, die de Heer IDE meebracht, behooren voor 't meerendeel tot de soort Aphodius fimetarius L., een geringer aantal behoorde tot de soort Aphodius ater de Geer.

Aphodius fimetarius varieert in lengte tusschen $5^{1 / 2}$ en 8 $\mathrm{mM}$; hij is zwart, zoowel aan de rugzijde als aan de buikzijde; de dekschilden echter zijn helderrood. 't Is eene zeer algemeen voorkomende soort, die vooral in paardemest en koemest wordt gevonden. 
Aphodius ater heeft een lengte van $5-6 \mathrm{mM}$. en is geheel zwart. Zij komt volgens Everts („Coleoptera Neerlandica”, II, blz. 26) hoofdzakelijk voor in koe- en schapemest, maar ook in vette tuinaarde.

Daar de champignonkultuur in ons land niet bijzonder veel wordt beoefend, zijn de vijanden dezer teelt hier te lande ook minder bekend; en zoo wist ik dan ook niet dat deze plaag in champignonkulturen meer voorkwam. Toch bleek mij weldra dat men in Frankrijk met de schade, door Aphodius fimetarius, teweeggebracht, wel op de hoogte is. Zoo vond ik deze soort vermeld in Cauchois "Manuel du champignonniste" (Paris, Librairie Horticole; 5ième édition, bl. 53.), en wel onder den naam le Suisse (de Zwitser). Uit het feit, dat de kevertjes bij de champignonkweekers in Frankrijk een populairen naam hebben, blijkt wel, dat zij daar tamelijk vaak in den paardemest der champignonkelders voorkomen Intusschen schijnt nog geen eenigszins afdoend bestrijdingsmiddel bekend te zijn. Bij hun wroeten in den mest, vallen er vele kevertjes in de paden tusschen de dijkjes van mest, in welke men de champignons teelt. Natuurlijk kan men, bij het opnieuw uitgraven der paden, de daaruit weggehaalde aarde, die soms wemelt van kevertjes, vermengen met ongebluschte kalk, die men door overgieting met water gaat blusschen. De aldus ontwikkelde hitte doodt de kevertjes.

J. RITZEMA BOS.

\section{Mededeelingen der Nederlandsche Phytopathologische Vereeniging.}

Naar aanleiding van hetgeen ik op de laatste bladzijde van den vorigen jaargang schreef, heeft de Heer K. FenteneR van VLISSINGEN te Haarlem zijne bijdrage als donateur verdubbeld.

Verder traden als donateurs tot onze Vereeniging toc de Herren A. W. Insinger te Bennekom en G. van der Veen te Rotterdam. J. RITZEMA BOS. 


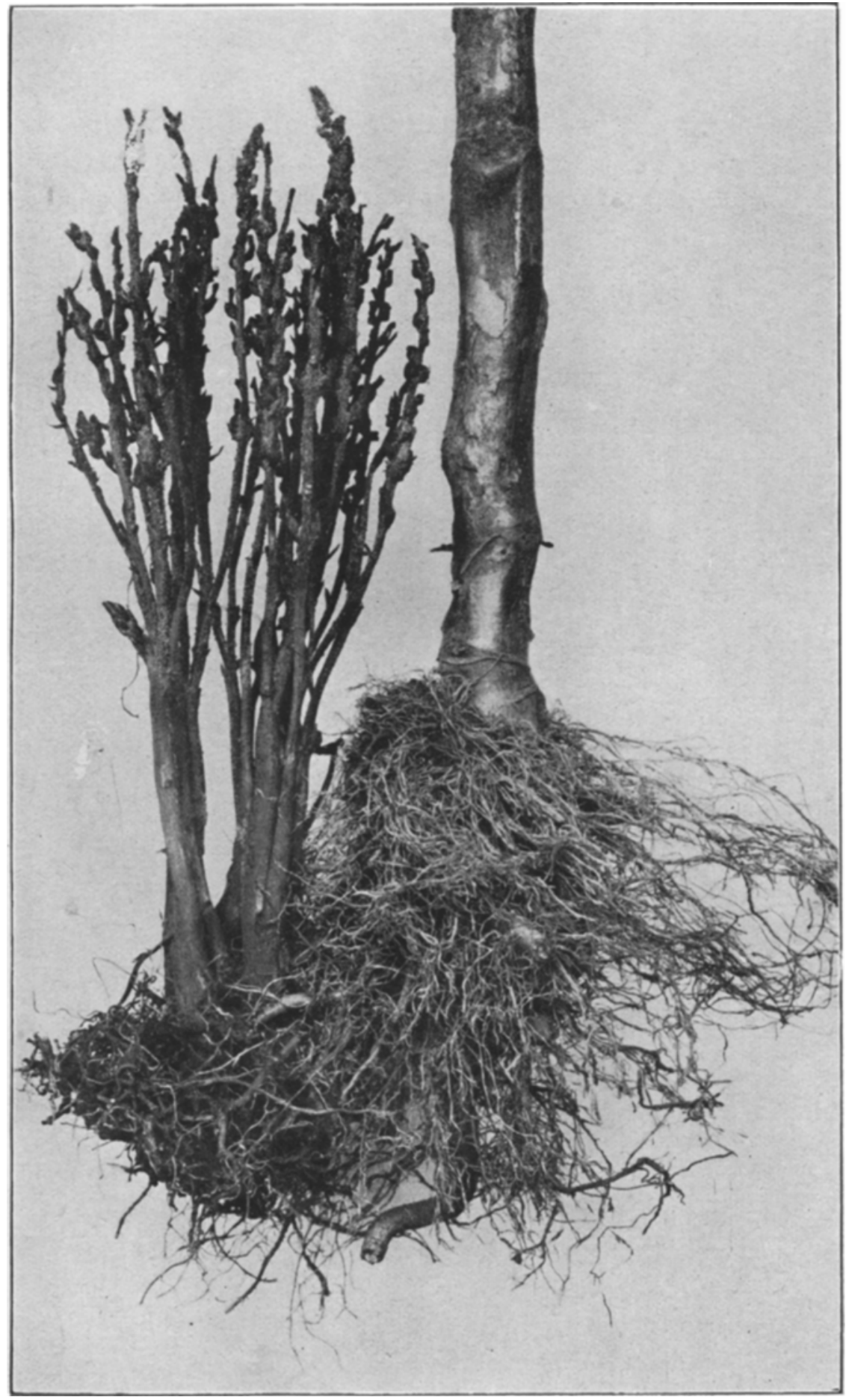




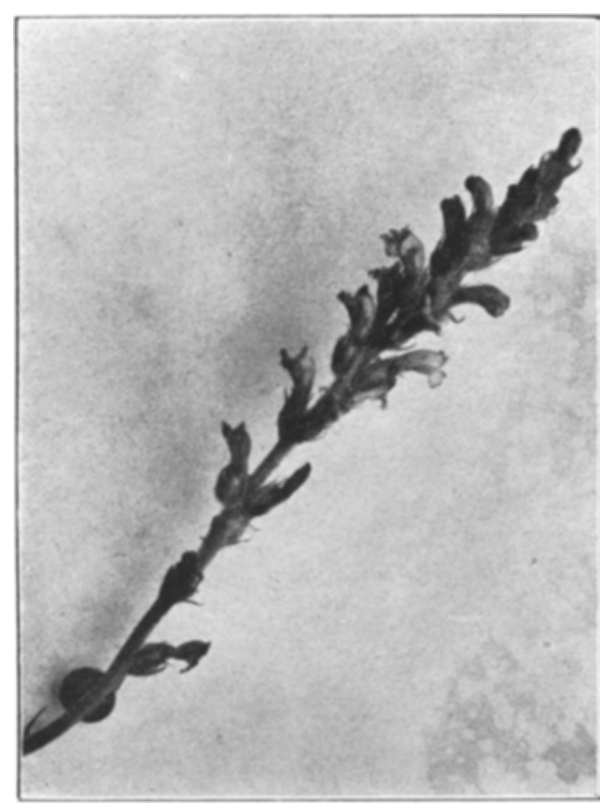

Fig. 1.
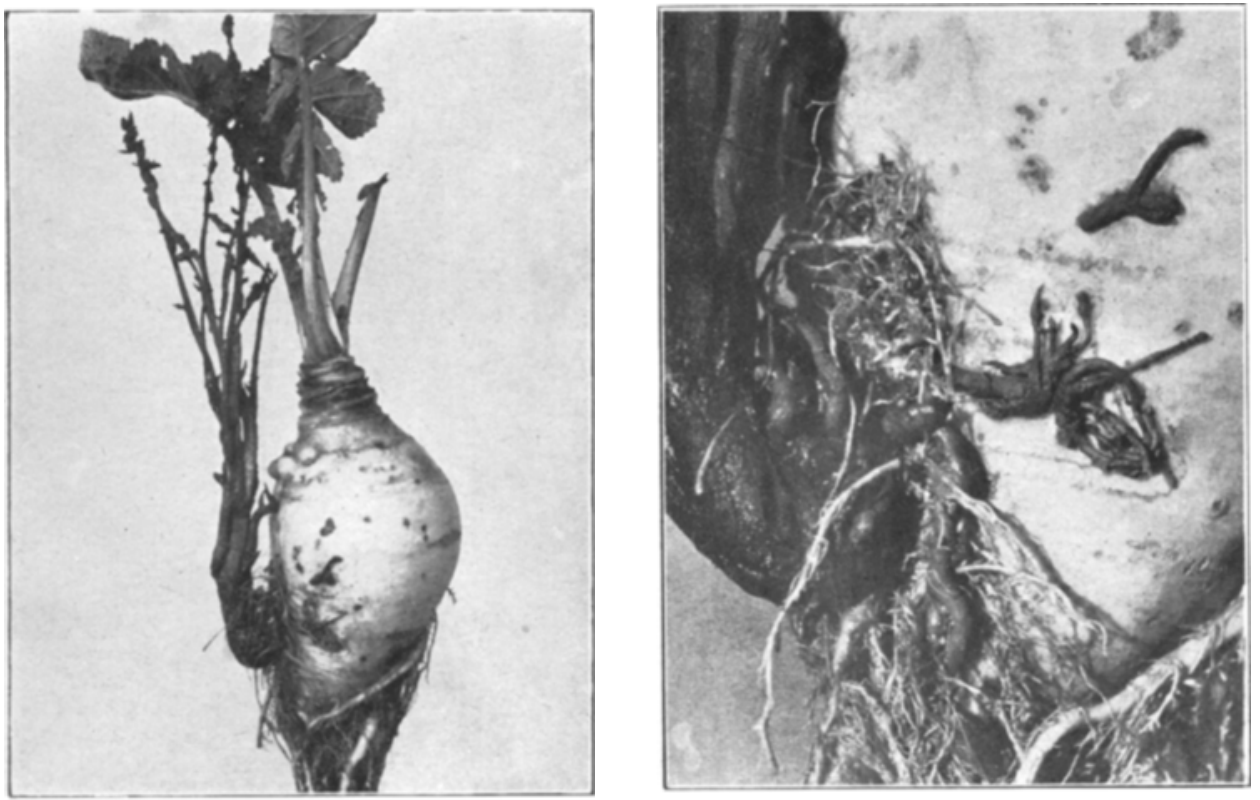

Fig. 2.

Fig. 3. 